DOI 10. 18307/2022. 0122

(C) 2022 by Journal of Lake Sciences

\title{
陕北定边盐湖卤水水位历史演变及其气候指示意义(1265-1949 年)
}

\author{
董凌霄, 费 杰* \\ (复旦大学历史地理研究中心, 上海 200433)
}

\begin{abstract}
摘 要: 受自然环境和资料限制的原因, 中国西北的季风边缘区内的湖泊千一百年时间尺度演变序列重建工作存在不足. 历史文献中的湖泊演变信息丰富, 有效利用可较好地解决这一问题. 本文通过梳理历史文献记录的定边盐湖采盐方式资 料, 反演历史时期定边盐湖卤水水位, 重建公元 1265-1949 年陕北定边盐湖卤水水位演变序列, 该序列较好地指示出公 元 1265-1949 年间定边盐湖所处区域的气候干湿变化状况. 重建结果显示, 定边盐湖所处区域在公元 1265-1949年间 存在 2 个湿润期和 3 个干旱期, 影响该区域气候干湿变化的主要原因为东亚夏季风的强弱变化. 本文研究证明历史文献 中的湖泊演变信息是一类科学的自然代用指标, 其便于收集、物理逻辑清晰, 但时间分辨率稍显不足, 若能与传统湖泊沉 积资料有效结合,具有更广阔的研究前景.
\end{abstract}

关键词: 定边盐湖群;季风边缘区;干湿变化;湖泊演变;历史文献;中国西北

\section{Historical records for the brine levels of Dingbian salt lakes (northern Shaanxi Province) and climatic implications, 1265-1949*}

\author{
Dong Lingxiao \& Fei Jie ** \\ (Center for History Geography Studies, Fudan University, Shanghai 200433, P.R.China)
}

\begin{abstract}
Due to the limitation of physical environment and data, the reconstruction of lake evolution at thousand/hundred year scales in the monsoon marginal zone of northwestern China has remains insufficient. The lake evolution information in historical documents is abundant, which can help better understand this issue. This paper combs the salt mining method data of Dingbian salt lakes recorded in historical documents, inverts the brine level of Dingbian salt lakes in the historical period, and reconstructs the evolution sequence of the brine level of Dingbian salt lakes in northern Shaanxi Province from 1265 A.D. to 1949 A.D.. We suggest that this sequence is a good indication of the climate change in the area from 1265 A.D. to 1949 A.D.. The reconstruction results show that there were two humid periods and three drought periods in the area over 1265-1949 A.D.. The main reason for the climage changes in this area was the intensity variation of the East Asian summer monsoon. Our research proves that the salt lake evolution information in historical literature is a kind of alternative indicator. It is easily available and has clear physical logic, but the time resolution is slightly ambiguous. Being combine with traditional lake sedimentation data, it will have a much broader study prospect.
\end{abstract}

Keywords: Dingbian salt lakes; monsoon marginal zone; dry wet variation; lake evolution; historical literature; northwestern China

亚洲季风系统影响了全世界超过一半的人口,亚洲季风系统在不同时间尺度上的演变规律是当代重要 的科学问题 ${ }^{[1-3]}$. 季风边缘区是指受夏季风环流影响气候年际波动较大的外围边界区, 具有生态脆弱性和气 候敏感性,是反映季风演变及其区域影响的重要区域,是对全球环境变化响应的敏感地区,也是全球环境变 化的关键区域,具有指示亚洲季风系统演变的重要意义 ${ }^{[4-6]}$.

中国季风西北缘区紧邻干旱区,下垫面状况比较特殊,是我国沙地和沙漠化土地的集中分布地区,这里 不仅是干湿冷暖的过渡带, 而且还是地貌型、植被型、土壤型、内外流域的过渡带和农牧交错带, 属于典型过

* 2021-03-08 收稿;2021-06-24 收修改稿.

国家科技基础资源调查专项课题 (2017FY101002) 资助.

** 通信作者;E-mail:jiefei@ fudan.edu.cn. 
渡地带. 诸多学者从不同角度研究该区域古气候、古环境演化以及对全球变化的区域响应等问题 ${ }^{[7-9]}$, 建立 环境演变序列,在地质尺度、轨道尺度和万年时间尺度研究中得出了有价值的科学理论. 但千一百年时间尺 度的研究受限于区域自然环境特点与技术手段, 难以选取满足千一百年尺度研究需求的自然代用指标, 导致 相关环境演变和气候干湿演变序列的重建工作较少,存在一定空缺.

中国西北的季风边缘区内湖泊广布,湖泊环境演替序列是研究不同时间尺度气候变化的重要依据 ${ }^{[10]}$. 前人学者利用传统湖泊沉积资料对季风边缘区内的岱海 ${ }^{[1-14]}$ 、青海湖 ${ }^{[15]}$ 等湖泊千年时间尺度变化情况进行 研究, 成果斐然. 但千年时间尺度研究对湖泊沉积环境要求较高, 中国西北的季风边缘区满足要求的湖泊较 少. 中国历史文献中记录了大量湖泊演变的信息, 利用历史文献复原湖泊演变过程也是历史地理学的经典 课题之一, 在东部季风区的湖泊研究中取得了诸多成果 ${ }^{[16-18]}$. 利用历史地理学方法可准确提取文献记录的 湖泊水位、水量、形态变化等信息,此类信息兼顾湖泊演替记录的敏感性和历史文献资料的准确性特征,可 识别和过滤人类活动对湖泊演变的干扰. 利用历史地理学湖泊演变研究的方法对中国西北季风边缘区内的 湖泊进行研究, 可为该区域湖泊研究提供一套全新的研究数据.

本文选取陕西省定边县的定边盐湖为研究对象. 定边盐湖位于毛乌素沙地南缘, 南部为黄土高原, 是典 型的中国西北季风边缘区过渡地带的湖泊. 定边盐湖自汉代以来设立盐官,一直是中国西北地区重要食盐 生产基地, 相关历史文献记载丰富. 本文通过提取历史文献中的定边盐湖公元 1265-1949 年采盐方法演变 的资料, 反演定边盐湖卤水水位变化情况, 建立湖泊卢水水位演替序列, 该序列可很好地指示盐湖所在区域 地气候干湿变化情况,这为深人了解历史时期季风边缘区气候变化提供了较好的数据支持.

\section{1 定边盐湖群概况}

陕北定边盐湖群 $\left(37^{\circ} 30^{\prime} \sim 37^{\circ} 50^{\prime} \mathrm{N}, 107^{\circ} 20^{\prime} \sim 107^{\circ} 50^{\prime} \mathrm{E}\right.$ ) 分布于陕西西北部定边县境内约 $1600 \mathrm{~km}^{2}$ 范围 内, 地处毛乌素沙地南缘, 黄土高原北部. 区域内的河谷侵蚀洼地或沙漠丘间洼地中形成众多盐湖, 现存较 大盐湖有花马池、烂泥池、波罗池、莲花池和红崖池等, 平均海拔 $1400 \mathrm{~m}$, 呈北东一南西向弧形排列, 成群分 布, 构成带状盐湖群. 湖区气候干旱, 年平均气温 $7 \sim 8^{\circ} \mathrm{C}$, 年降水量 $200 \mathrm{~mm}$ 左右, 年蒸发量达 $2800 \mathrm{~mm}$, 年日 照时数 $2900 \mathrm{~h}$, 属于半干旱大陆性气候区 ${ }^{[19]}$.

定边盐湖群湖盆为古河谷侵蚀盆地, 边缘有少量第三纪砂岩、泥岩沉积, 并有第四纪黄土沉积, 形成湖 堤和台地. 定边盐湖群所在丘间盆地自成独立小流域, 盆地内降水快速渗人地下形成地下水, 汇流人花马池 盐湖, 汇流面积为 $197.89 \mathrm{~km}^{2}$. 盆内第四纪冲积、风积和湖积沙砾石、粉细砂、粉砂黏土和盐类化学沉积广布. 盐湖水化学类型为硫酸盐型硫酸镁亚型, 固体盐类资源有石盐和芒硝, 以石盐为主. 盐湖卤水以湖表卤水形 式赋存于湖盆内, 是生产湖表石盐和滩晒再生盐的主要矿源 ${ }^{[20]}$.

定边盐湖群具体情况见表 1 , 其中花马池盐湖面积最大, 估算石盐储量达 140 万 $\mathrm{t}$, 依靠大气降水和地下水 补给, 产盐环境稳定, 是盐湖群的核心盐湖; 其余盐湖与花马池统属一个丘间盆地, 地质地貌条件与花马池相 似 ${ }^{[20]}$. 本研究以定边盐湖的花马池盐湖为主要研究对象, 其余盐湖作为参考盐湖. 图 1 中标示的苟池与花马池 距离相近,但两湖不属于同一丘间盆地, 影响因素差异较大,参考价值低,本文不将其列人研究范围.

定边盐湖在历史时期是我国西北部重要的湖盐生产基地. 汉代始, 定边盐湖设置盐官; 唐宋时期定边盐 湖群统称乌池, 所产青盐是西北重要的战略物资; 元代时, 与宁夏境内盐湖统称韦红盐湖, 供周边人群食用. 公元 1370 年, 明朝设置灵州盐课巡检司, 专门管理定边盐湖产销, 其中花马池称大盐池, 其余烂泥、波罗、连 环等盐湖产销归属大盐湖统一管理; 公元 1730 年, 清朝于定边设县, 定边盐湖群归属定边县管理, 称为定边 盐湖或花马诸池 ${ }^{\mathbb{D}[21-22]} ; 1990 \mathrm{~s}$ 以来, 随着盐环定扬黄工程完工, 定边县内生活、生产用水增多, 城市污水流人

(1) 对于花马池的沿革考证目前尚无专篇论文进行论述, 作者综合现有观点进行考证. 马孟龙根据出土封泥资料考证认 为, 花马池所在区域应为汉代上郡龟兹县, 据《汉书・地理志》: “龟兹, 属国都尉治. 有盐官”, 表明花马池在汉代时已设盐 官管理. 唐代乌池位于盐州, 据陈永中考证盐州位于今定边县境内, 乌池即今定边盐湖统称. 明代时, 花马池时称大盐池, 并于洪武三年设置盐课提举司进行管理, 明代文献以及古地图皆使用大盐池以命名今花马池. 明代文献中的花马池应为 今北大池盐湖, 位于长城外, 据《中国历史地图集》, 北大池又名旧花马池, 后花马池营内迁至今盐池县, 湖名亦随之内迁. 清代雍正时, 《陕西通志》始称为花马池, 后延续至今. 
花马池盐湖,该盐湖水量明显增加, 现已不产盐.

表 1 定边盐湖群基本信息 ${ }^{(1)}$

Tab.1 Basic information of Dingbian salt lakes

\begin{tabular}{|c|c|c|c|c|c|c|}
\hline 盐湖 & 经纬度 & 盐湖面积 & 高程 & 水深 & 补给类型 & 固体石盐层厚度 \\
\hline 花马池 & $37^{\circ} 41^{\prime} 20^{\prime \prime} \mathrm{N}, 107^{\circ} 30^{\prime} 15^{\prime \prime} \mathrm{E}$ & $24 \mathrm{~km}^{2}$ & $1310 \mathrm{~m}$ & $0.1 \mathrm{~m}$ & $\begin{array}{l}\text { 大气降水 } \\
\text { 地下水 }\end{array}$ & $\begin{array}{c}\text { 深层 } 1.02 \mathrm{~m} \text { 粗粒状固体盐沉积 } \\
\text { 表层 } 0.25 \mathrm{~m} \text { 粒状湖表卤水新沉积石盐 }\end{array}$ \\
\hline 滥泥池 & $37^{\circ} 35^{\prime} 20^{\prime \prime} \mathrm{N}, 107^{\circ} 25^{\prime} 10^{\prime \prime} \mathrm{E}$ & $5 \mathrm{~km}^{2}$ & $1322 \mathrm{~m}$ & $0.5 \sim 0.12 \mathrm{~m}$ & $\begin{array}{l}\text { 大气降水 } \\
\text { 地下潜水 }\end{array}$ & $0.05 \sim 0.12 \mathrm{~m}$ \\
\hline 波罗池 & $37^{\circ} 32^{\prime} 05^{\prime \prime} \mathrm{N}, 107^{\circ} 24^{\prime} 15^{\prime \prime} \mathrm{E}$ & $5.5 \mathrm{~km}^{2}$ & $1339 \mathrm{~m}$ & $0.1 \mathrm{~m}$ & $\begin{array}{l}\text { 大气降水 } \\
\text { 地下潜水 }\end{array}$ & $0.02 \sim 0.05 \mathrm{~m}$ \\
\hline 莲花池 & $37^{\circ} 35^{\prime} 15^{\prime \prime} \mathrm{N}, 107^{\circ} 30^{\prime} 10^{\prime \prime} \mathrm{E}$ & $4 \mathrm{~km}^{2}$ & $1340 \mathrm{~m}$ & $0.05 \mathrm{~m}$ & $\begin{array}{l}\text { 大气降水 } \\
\text { 地下潜水 }\end{array}$ & 新盐沉积, 薄层状 \\
\hline 红崖池 & $37^{\circ} 30^{\prime} 07^{\prime \prime} \mathrm{N}, 107^{\circ} 27^{\prime} 30^{\prime \prime} \mathrm{E}$ & $3 \mathrm{~km}^{2}$ & $1330 \mathrm{~m}$ & $0.1 \mathrm{~m}$ & $\begin{array}{l}\text { 大气降水 } \\
\text { 地下潜水 }\end{array}$ & 表层新盐沉积 \\
\hline
\end{tabular}

图 1 中标示了本文研究区域概况以及本文选用比对的相关代用资料. 其中, 湖泊沉积记录为内蒙古凉 城县境内的岱海和青海省的青海湖, 树木年轮资料有过去 $1230 \mathrm{a}$ 柴达木盆地东部树木年轮资料, 石笋资料 为甘肃万象洞石笋. 而历史文献资料多为地方志资料, 本文选取宁夏、陕西、甘肃三省区现存省志、府志和县 志资料,共 13 部.

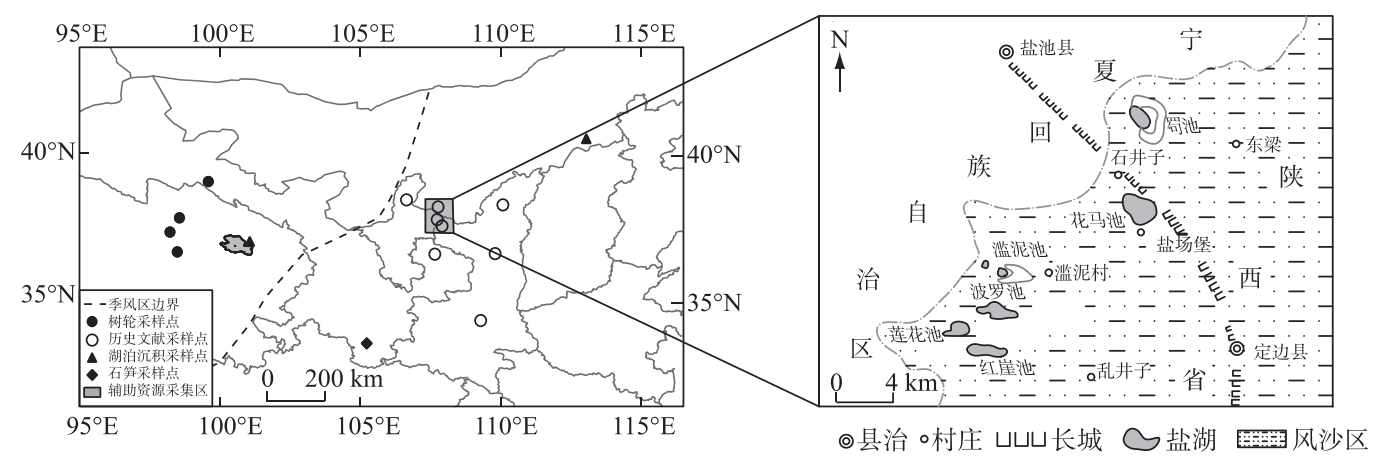

图 1 研究区域及数据采集点

Fig.1 Study area and data collection points

\section{2 方法与资料}

\section{1 资料}

本文所用资料出自历史文献, 通过系统查阅二十四史、1949 年之前地方志及史部著述, 以及部分明清时 期档案、笔记、日记、文集等文献, 共查出相关资料 23 条. 资料分为核心资料和辅助资料两类, 核心资料记载 陕北定边盐湖群的核心花马池的采盐方法, 共 17 条, 见表 2 ; 辅助资料为该区内其余小盐湖变化, 区域开发、 牧马规模等资料,共 6 条, 见表 3.

本研究所用资料为历史文献记录的盐湖史料,此类资料信息指示明确,核心资料为花马池盐湖的采盐 方式记录, 辅助资料为指代区域气候干湿的农牧业发展资料, 可避免资料混用或错用. 资料包含内容丰富, 单条资料信息丰富,单条史料至少包含了时间、相关盐湖、开采方式 3 类信息,内容清晰明确, 反映信息可

(1) 该表数据来源于《中国盐湖志》, 其中高程数据仅记录花马池、苟池两湖, 其余各湖的高程通过天地图-国家地理信息 公共服务平台 (https://www.tianditu.gov.cn/) 的高程数据补足. 
靠,资料的准确性有保障.

表 2 研究选用的花马池盐湖采盐方法

Tab.2 Salt mining method of the Huamachi salt lake

\begin{tabular}{|c|c|c|c|}
\hline 序号 & 资料内容 & 文献来源 & $\begin{array}{l}\text { 文献出现时间 } \\
\text { (A.D.) }\end{array}$ \\
\hline 1 & $\begin{array}{l}\text { 宁夏所产韦红盐湖……所产韦红盐, 池不办课程……解盐结之于风, 韦 } \\
\text { 红之盐产之于地. }\end{array}$ & 《元史》卷 99 & 1265 年 \\
\hline 2 & 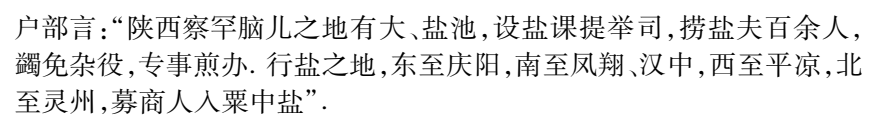 & 《明太祖实录》卷 59 & 1370 年 \\
\hline 3 & $\begin{array}{l}\text { 盐池之在宁夏界内者,大盐池在三山儿东, 小盐池在韦州东北. 国朝设盐 } \\
\text { 课司, 收积池盐,以待客商支给. }\end{array}$ & 《宁夏志》卷 28 & 1436 年 \\
\hline 4 & $\begin{array}{l}\text { 盐池在府城北五百里池有二,大盐池周围八十里, 小盐池周围二十七里, } \\
\text { 俱产盐. }\end{array}$ & 《明一统志》卷 36 & 1452 年 \\
\hline 5 & $\begin{array}{l}\text { 今盐池之在三山儿者曰大盐池,在故盐州城之西北者曰小盐池 } . . . . . \text { 其盐 } \\
\text { 不劳人力,水泽之中,雨少因风,则自然而生矣. }\end{array}$ & 弘治《宁夏新志》卷 3 & 1500 年 \\
\hline 6 & $\begin{array}{l}\text { 今盐池之在三山儿者, 日大盐池 } \cdots \cdots \cdot \text { 其盐不劳人力, 水泽之中, 雨少因 } \\
\text { 风,则自然而生矣. }\end{array}$ & 嘉靖《宁夏新志》卷 3 & 1540 年 \\
\hline 7 & $\begin{array}{l}\text { 盐池,在府北五百余里. 池有二:大池自沙漠中来,周八十里;小盐池控灵 } \\
\text { 夏郡, 周二十七里,俱产盐. }\end{array}$ & 嘉靖《陕西通志》卷 4 & 1542 年 \\
\hline 8 & 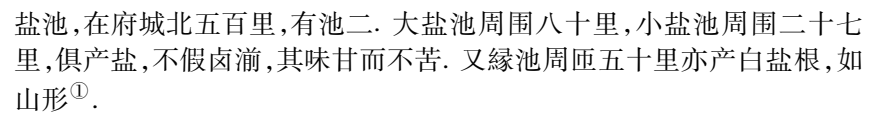 & 嘉靖《庆阳府志》 & 1557 年 \\
\hline 9 & 旱港不常, 盐花少结, 所捞不及十之五六. & 《明神宗实录》卷 371 & 1602 年 \\
\hline 10 & $\begin{array}{l}\text { 至于大盐池则在边,尝闻之土人, 小盐池井畦尚烦人力,乃大盐池则天产 } \\
\text { 自然之利也 } \cdots \cdots \cdot \text { 况先是大盐池之行兼延庆而有之,迩年灵州以小盐池请 } \\
\text { 庆阳专行焉, 而大池阙矣. }\end{array}$ & 万历《延绥镇志》卷 2 & 1607 年 \\
\hline 11 & $\begin{array}{l}\text { 今盐池之在三山儿者曰大盐池,在故盐州城之西北者曰小盐池,其他名 } \\
\text { 孛罗等池最多,皆分隶大盐池. 其盐大都不劳人力, 因风自生,殆天产以 } \\
\text { 资我边需者也. }\end{array}$ & 万历《朔方新志》 & 1614 年 \\
\hline 12 & $\begin{array}{l}\text { 又二十里为盐场堡, 有大盐池, 周围三里许, 中有井, 引水湛畦, 一昔视之 } \\
\text { 若积雪焉. 此九种之一也. }\end{array}$ & 康熙《延绥镇志》卷 1 & 1673 年 \\
\hline 13 & $\begin{array}{l}\text { 花马大池,坐落榆林府定边县地方, 距府六百里, 距县城二十里, 周围一 } \\
\text { 十六里. 每年二月间于池内开治坝畦,引水人池灌畦, 风起波生,日晒成 } \\
\text { 盐,用力极易, 唯天早少水或雨水过溢,,所产差少. }\end{array}$ & 雍正《陕西通志》 & 1734 年 \\
\hline 14 & $\begin{array}{l}\text { 池周十六里许, 南风至, 即水成盐, 自然凝结. 盐场堡每年二月间于池内 } \\
\text { 开治坝畦,引水人池灌畦, 风起波生, 日晒成盐, 用力极易. 惟天旱少水或 } \\
\text { 雨水过溢, 所产差少. }\end{array}$ & 嘉庆《定边县志》卷 12 & 1817 年 \\
\hline 15 & $\begin{array}{l}\text { 盐场堡每年二月间于池内开治坝畦,引水人池灌畦, 风起波生, 日晒成 } \\
\text { 盐,用力极易,惟天旱少水或南水过溢,,所产差少. }\end{array}$ & 道光《榆林府志》卷 23 & 1841 年 \\
\hline 16 & $\begin{array}{l}\text { 大花马池所产之盐名曰花盐, 不假人工, 天然生产. 每年春末夏初, 雨水 } \\
\text { 露足而又晒曝适时, 既能凝结成盐. 夏季, 盐已成熟, 土著客籍均得人池, } \\
\text { 捞取于池畔堆积, 以土復之, 待价而沽. }\end{array}$ & 民国《盐池县志》 & 1913 年 \\
\hline 17 & $\begin{array}{l}\text { 经后勤部一年努力, 打盐井、筑盐坝、辟盐田,盐产量顿增, } 1941 \text { 年计产盐 } \\
702,513 \text { 㭈. }\end{array}$ & 《盐池县志》1983 年版 & 1941 年 \\
\hline
\end{tabular}

(1) (明) 傅学礼: 嘉靖《庆阳府志》,《域外汉籍珍本文库》第三辑 [蕒拾参]. 北京: 人民出版社, 2012 年. 
表 3 研究所选用的相关辅助资料

Tab.3 The supplementary information

\begin{tabular}{|c|c|c|c|c|}
\hline 序号 & 资料内容 & 资料类型 & 资料来源 & $\begin{array}{c}\text { 资料出现时间 } \\
\text { (A.D.) }\end{array}$ \\
\hline 1 & $\begin{array}{l}\text { 洪武三十年正月 } \cdots \cdots . . .1 \text { 自雁门关外, 西抵黄河, 渡河至察 } \\
\text { 汗脑尔, 又东至紫荆关……凡军民屯种田地, 不许放牧, } \\
\text { 掔畜其荒闲平地, 及山场, 腹内诸王、驸马及极边军民听 } \\
\text { 其放牧樵采. }\end{array}$ & 区域牧业资料 & 《明太祖实录》卷 249 & 1397 年 \\
\hline 2 & $\begin{array}{l}\text { 永乐四年九月壬戌, 设陕西、甘肃二苑马寺 } . . . . . . \text { 清平、万 } \\
\text { 安隶灵武监……春月草长, 纵马于苑, 迨草枯则收饲之. }\end{array}$ & 区域牧业资料 & 《明太宗实录》卷 59 & 1406 年 \\
\hline 3 & $\begin{array}{l}\text { 国朝之牧苑, 在宁夏界者二: 清平苑, 在三山儿东; 万安 } \\
\text { 苑, 在大盐池南. }\end{array}$ & 区域牧业资料 & 《宁夏志》卷 32 & 1436 年 \\
\hline 4 & $\begin{array}{l}\text { 诏宁夏以淮浙两运司盐召商中马. 时宁夏内外守臣王清 } \\
\text { 等奏, 宁夏三路旧马一万百余匹, 选调亡失之余 } \\
\text { 止存六百. 罢驽半之, 虽令以灵州盐课中纳, 自沿边被 } \\
\text { 掠, 兼以盐池寇盗, 所经商旅罕至. }\end{array}$ & 区域牧业资料 & 《明宪宗实录》卷 39 & 1467 年 \\
\hline 5 & 波罗池, 水池, 不产盐. & 其余盐湖变化 & 嘉庆《定边县志》 & 1817 年 \\
\hline 6 & $\begin{array}{l}\text { 烂泥池等所产, 名曰浪盐, 生产则半由人力. 春夏之交, } \\
\text { 土人于池内开治坝畦, 引水灌溉, 如田之下种, 故又名种 } \\
\text { 盐……波罗池向不产盐, 另有红崖池、娃娃池, 晚近更无 } \\
\text { 出产, 日久沙雍, 旧迹尽泯. }\end{array}$ & 其余盐湖变化 & 民国《盐池县志》 & 1913 年 \\
\hline
\end{tabular}

盐湖开采方式记录是本研究主要运用的资料. 盐湖开采方式是历史文献中记录数量较多的一类资料, 传统时代的采盐方式遵循经济最大化原则, 多根据盐湖自然状态进行选择, 因此该类记录可反演历史时期 盐湖的水位、水量等自然状况. 此类记录多出自正史、实录和地方志等资料, 单条资料出现的时间是具体的 单一年份, 容易造成该资料仅代表该年份情况而不具备代表性的误解. 正史、实录和地方志的编纂是为了总 结此前一个时段内的情况, 这也决定了此类记录中的开采方式是此前长时间段内的普遍方法, 而非反映单 一年份的情况,资料本身具有时间延续性和代表性.

资料分布时间上限为公元 1265 年,下限为公元 1949 年. 公元 1500 年前资料共有 4 条,多来源正史、实 录和全国地理总志记载, 其余资料多来自公元 1500 年后, 大量地方志资料出现, 使记载数量明显增多, 资料 质量也较之前更高. 资料数量较小, 时间分辨率较低, 历史文献的编纂受到区域发展的限制明显, 数据时间 分布不均匀,连续性较差, 无法做到均一识别.

基于本文所选用的资料特性,本文序列重建尊重逐条资料所反映的情况,保证各条资料信息准确的前 提下形成各时间点位, 对各点位进行缀连, 形成本文的序列.

\section{2 方法}

2.2.1 湖泊信息提取 本研究使用文献分析方法, 利用历史学分析方法, 准确提取文献资料记载的盐湖信息, 并通过所提取信息来转换分析陕北定边盐湖群所处区域内的干湿变化状况.

区域第四系浅层地下水水位高低是反映该区域的气候干湿状况波动的重要指标. 定边盐湖所处区域内 的第四系地下水位主要靠大气降水补给, 大气降水是定边盐湖所处区域内第四系浅层地下水补给的主要来 源, 部分地区也受深层承压地下水补给, 但分布十分有限 ${ }^{[23]}$. 陕北定边盐湖所在丘间盆地无常年性地表水 流人, 每年有限的降水迅速渗人砂层形成地下水,一般不形成地表径流, 很快汇人洼地中心的盐碱湖滩 ${ }^{[20]}$. 在无人为调水调蓄影响的情况下, 气候干湿状况对地下水水位具有直接的影响, 气候湿润时期浅层地下水 水位较高,气候干旱时期,浅层地下水水位较低.

定边盐湖内的湖表卢水水量与区域地下水位具有明确关系. 定边盐湖位于盐池台地内流区, 现代水网 极不发育, 全区第四系浅层地下水埋深普遍较浅. 定边盐湖的核心花马池盐湖所处的盐场堡一带, 地下水埋 深小于 $1.5 \mathrm{~m}$, 盐湖边缘附近地下水位更浅, 普遍小于 $1 \mathrm{~m}^{[19]}$, 盐湖卤水以第四系浅层地下水出露的形式赋 
存于湖盆内. 在自然状态下, 定边盐湖中花马池的卤水水位可直接视为区域第四系浅层地下水水位, 盐湖内 卤水水量大时, 浅层地下水水位高, 而盐湖卤水量少时, 浅层地下水位低. 花马池盐湖处于丘间盆地中最低 处,整个丘间盆地的水最后都汇于此后蒸发, 因此花马池盐湖中也留存了最厚的盐类沉积层. 这也表明,花 马池卤水水位季节性变化受雨季降水影响大,但是长时期的水位高低, 与其所处的丘间盆地内的水量平衡 和干湿状态关系更近, 暴雨类降水或雨季集中降水并不会影响长时间段花马池盐湖的卤水水位. 在无远距 离调水工程影响的传统时代, 花马池盐湖的湖表卤水水量可视为界定该区域气候干湿变化的重要代用指标.

花马池盐湖为硫酸盐型硫酸镁亚型盐湖, 春夏季产盐, 秋冬季产芒硝 ${ }^{[20]}$, 其位于内蒙古、陕西和宁夏三 省交界处, 11 月一次年 2 月温度较低, 盐湖卤水中存在大量芒硝和冰, 进人 3 月份后温度缓慢回升, 冰和芒硝 溶解, 到 4 月份平均温度达到 $10^{\circ} \mathrm{C}$, 卤水中的固相盐基本溶解完全, 盐湖的蒸发量主要集中在 4-10 月, 此 外的月份, 温度和日照条件皆无法满足产盐的需求, 石盐开采时间集中于 4-10 月这一时段. 传统时代,盐 湖开采方式是根据盐湖长期卤水水位高低, 而相应移动的开采面进行盐生产, 因此盐湖开采方式可反映盐 湖长期卤水面的情况. 历史文献记录的开采方式有 4 类, 详见表 4. “井盐”、“畦盐”、“花盐” 3 种方法自唐代 即采用, 是盐湖处于自然状态下始终运用的 3 种方法. 而盐坝产盐则出现在清代, 其目的为降低雨季降水对 产盐的影响, 降水会导致卤水淡化, 从而不产盐, 因此人类在湖盆中修筑盐田, 田内修筑排水沟渠, 可将多余 降水排出, 从而保证在雨季降水偏多的情况下仍能持续采盐, 其工程介人程度不深, 并未改变盐湖卤水提取 方法,可视为 “花盐” 在降雨较丰富的情况下的方法变种. 其次, 这样的工程也恰好表明利用这一方式采盐的 时段,气候应更加湿润, 雨季降水量较多.

通过分析表 4 , 发现花马池盐湖的湖表卤水水量决定了开采方式的选择, 当湖内卤水为常年性卤水时, 需将卤水引出池外盐田滩晒; 若湖表卤水为季节性卤水, 且水量较小, 则可在湖盆内直接滩晒, 若季节性卤

表 4 历史文献中盐湖开采记录的指示意义

Tab.4 Indicative significance of salt lake mining records in historical documents

\begin{tabular}{|c|c|c|c|c|c|}
\hline 名称 & 生产时间 & 示例 & 盐湖卤水情况 & 盐湖开采方式 & $\begin{array}{l}\text { 指示地 } \\
\text { 下水位 }\end{array}$ \\
\hline “畦盐” & $4-10$ 月 & $\begin{array}{l}\text { 作 “畦”, 若种非一畦. 天雨下, 池 } \\
\text { 中咸淡得均, 即畎池中水上畔中, } \\
\text { 深一尺许 (坑), 日暴之五、六日 } \\
\text { 则成 }{ }^{(1)} \text {. }\end{array}$ & $\begin{array}{l}\text { 盐湖中存有丰富常 } \\
\text { 年性盐湖卤水. }\end{array}$ & $\begin{array}{l}\text { 于盐湖边修筑水沟和 } \\
\text { 盐田, 将湖表卤水引 } \\
\text { 人盐田后进行滩晒. }\end{array}$ & 高 \\
\hline 盐坝产盐 & $4-10$ 月 & $\begin{array}{l}\text { 每年二月间于池内开治坝畦, 引水 } \\
\text { 人池灌畦, 风起波生, 日晒成盐, 用 } \\
\text { 力极易, 唯天旱少水或雨水过溢, } \\
\text { 所产差少 }{ }^{2} \text {. }\end{array}$ & $\begin{array}{l}\text { 盐湖区域雨季降水 } \\
\text { 丰富, 形成丰富的 } \\
\text { 季节性湖表卤水. }\end{array}$ & $\begin{array}{l}\text { 于盐湖湖盆内修筑盐 } \\
\text { 田, 将卤水引人盐田 } \\
\text { 滩晒, 盐田内有排水 } \\
\text { 渠, 可将多余降水排 } \\
\text { 出, 保障生产. }\end{array}$ & 较高 \\
\hline “花盐” & $4-10$ 月 & $\begin{array}{l}\text { 池中雨下, 随而大小成盐, 其下方 } \\
\text { 微空, 上头随雨下池中, 其滴高起 } \\
\text { 若塔子形处曰花盐, 亦曰即成盐 }{ }^{3} \text {. }\end{array}$ & $\begin{array}{l}\text { 季节性降水进人盐 } \\
\text { 湖湖盆, 形成少量 } \\
\text { 卤水, 蒸发后卤水 } \\
\text { 消失. }\end{array}$ & $\begin{array}{l}\text { 不需要人类工程介人 } \\
\text { 生产, 以天然湖盆作 } \\
\text { 为滩晒盐田即可. }\end{array}$ & 较低 \\
\hline “井盐” & $4-10$ 月 & $\begin{array}{l}\text { 池中並井深一、二尺, 去泥即到盐, } \\
\text { 掘取若至一丈, 则着平石无盐矣, } \\
\text { 其色或青或黑, 名曰井盐 }{ }^{4} \text {. }\end{array}$ & $\begin{array}{l}\text { 盐湖 湖盆内没 有 } \\
\text { 卤水. }\end{array}$ & $\begin{array}{l}\text { 直接开采盐类沉积矿 } \\
\text { 层,所产称石盐、青盐 } \\
\text { 或盐根. }\end{array}$ & 低 \\
\hline
\end{tabular}

(1) (唐) 张守节著:《〈史记〉正义》, 见《史记》, 中华书局, 1982 年版, 第 3260 页.

(2) (清) 刘於义修, 沈青崖纂: (雍正)《陕西通志》, 《中国地方志集成. 1-4. 省志辑》, 凤凰出版社(等), 2011 年.

(3) (唐) 张守节著:《〈史记〉正义》, 见《史记》, 中华书局, 1982 年版, 第 3261 页.

(4) (唐) 张守节著:《〈史记〉正义》, 见《史记》, 中华书局, 1982 年版,第 3261 页. 
水丰富, 则需在湖盆内修筑盐田, 排出多余卤水保证滩晒; 若无湖表卤水, 则直接开挖湖盆内的盐矿层, 与本 文所用资料对比发现, 本文所用资料无一记录超出表 4 的范围, 可以断定在传统时代, 这种关系是普遍且固 定的.

综合上述, 可以建立历史文献中的盐湖开采方式与气候干湿变化波动的关系:盐湖内卤水偏多, 盐湖开 采方式需人类工程介人, 表明定边盐湖所处区域浅层地下水水位高, 指示该时段内气候潮湿; 盐湖内卤水 少,开采无需工程介人,可直接滩晒,表明区域浅层地下水水位低,指示该时段内气候干燥.

需指出的是, 低温和日照时间少等情况会导致蒸发量减少, 从而影响湖表卤水水量, 但在采盐的 4-10 月时间段内, 这种情况是极端事件, 目前无法从技术上剔除这类事件影响, 但从这个意义上来讲, 这对我们 进行千一百年时间尺度的复原影响并不明显.

2.2.2 定级 根据资料特点与数量, 本文整理了公元 996-1949 年间历史文献中出现的定边盐湖开采方式的 记录, 采用模糊定量的方法, 对不同开采方式对应的区域地下水水位分级处理, 处理的标准为历史文献中的 盐湖开采方式记录的特点进行判定, 盐湖开采方式记录共有两类指标, 一为盐湖卤水的赋存情况, 一为人类 工程的介人情况. 其中历史文献中 4 类明确的盐湖开采方式都有完整的两类指标记载, 因此本研究根据盐 湖开采方式的文本记录是否满足这两种指标进行分级.

整理后发现, 历史文献中还有部分表述并不清晰的模糊记录. 此类记录的特点为表明盐湖利用湖盆季 节性卤水滩晒产盐, 无法判断盐湖卤水赋存情况, 且人类工程介人情况不明晰. 例如: “陕西察罕脑儿之地有 大盐池,设盐课提举司, 捞盐夫百余人,蠋免杂役, 专事煎办. ${ }^{\mathbb{1}}$ ”该时期内产盐方式为捞盐, 即利用湖盆内湖 表卤水生产, 但资料内容无法判断卤水多塞, 无人类工程介人情况记录, 为一条模糊记录. 从这类记录的内 容特点分析, 此类记录的记录特点介于盐坝产盐与 “花盐” 两种方式之间, 属于盐湖开采记录的中间级, 故将 其指示的地下水位状况也视为中间级处理.

本文将地下水水位情况分为 5 级处理,其中 1 级、 2 级、 4 级、 5 级中有明确的卤水赋存情况和人类工程 介人情况, 3 级为中间级,专为模糊记载定级. 详情见表 5 .

表 5 定边盐湖所处区域历史时期干湿状况判断指标

Tab.5 Evaluation index of dry and wet condition of Dingbian salt lakes in historical period

\begin{tabular}{ccccc}
\hline 等级 & 盐湖卤水情况 & 人类工程介人 & 地下水位情况 & 气候干湿状况 \\
\hline 1 级 & 湖盆内有常年性卤水 & 盐湖旁修筑盐田 & 高 & 湿润 \\
2 级 & 湖内季节性卤水丰富 & 盐湖湖盆内修筑盐坝、盐田 & 较高 & 偏湿 \\
3 级 & 季节性卤水产盐,卤水量不详 & 无人类工程记录 & 正常 & 正常 \\
4 级 & 盐湖季节性卤水较少 & 无需人类工程,自然滩晒 & 较低 & 偏干 \\
5 级 & 盐湖盆内无卤水 & 直接擦挖盐矿 & 干燥 & \\
\hline
\end{tabular}

3 级记录为模糊记录, 会影响序列准确性, 本文利用指示区域干湿状况的资料作为辅助指标, 辅助存在 3 级记录的时段定级. 辅助资料选用需满足区域条件和资料类型条件,所选辅助资料出现的区域限制为定边 盐湖所处的盐池沙地内,包括宁夏自治区盐池县、陕西省定边县, 以及甘肃省环县一部分; 资料类型为可指 示区域干湿变化的人类活动情况, 并按不同人类活动的需水量划分为 4 类,详情参见表 6 . 定边盐湖区域内 无常年性长流水, 水利工程缺乏, 属于雨养农业区和农牧交错带, 根据不同降水情况选择其发展的产业亦会 发生变动. 因此,盐池沙地内部的农业屯垦和牧业发展状况可一定意义上指示区域内的降水情况. 为保证本 文重建结果以湖泊演替为主要指标, 不受其余指标影响, 辅助指标的运用仅针对存在 3 级记录的时段, 若无 3 级记录则不使用辅助指标.

综上,具体定级方法为: 1) 盐湖开采方式资料定级以其记录内容满足各级的卤水赋存情况和人类工程 介人情况指标, 即可定级, 无需辅助指标参与. 2) 盐湖开采方式资料记录定级为 3 级, 则根据表 6 标准将存 在辅助资料的年份进行升降级调整. 3 ) 若 3 级记录出现时间段内无辅助资料, 则仍定为 3 级处理.

(1)《明太祖实录》,卷五九, “洪武三年十二月庚申”条, 台北, “中研院”历史语言研究所编,第 1148 页. 
表 6 盐池沙地农牧业发展的气候指示意义

Tab.6 The significance of climate indicators for the development of agriculture and animal husbandry in Yanchi sandy land

\begin{tabular}{|c|c|c|}
\hline 发展概况 & 示例 & 气候干湿状况 \\
\hline 屯垦面积显著增加 & 研究时段内无记录 & 湿润 \\
\hline $\begin{array}{l}\text { 无屯星记录 } \\
\text { 牧业发展良好 }\end{array}$ & 春月草长, 纵马于苑, 迨草枯则收饲之 ${ }^{(1)}$ & 偏湿 \\
\hline $\begin{array}{l}\text { 无法屯莀 } \\
\text { 牧业萎缩 }\end{array}$ & $\begin{array}{c}\text { 原皆沙蹟山冈, 开层徒费人工, 收获全无花利 } 2 \\
\text { 选调亡失之余止存六百, 罢驽半之 }\end{array}$ & 偏干 \\
\hline 牧业失效 & 研究时段内无记录 & 干旱 \\
\hline
\end{tabular}

\section{3 重建结果}

经过信息提取和定级处理后,各条资料出现年份的定级情况如表 7 所示. 公元 1265-1949 年间,共识 别出 5 级点位 0 个、 4 级点位 6 个、 3 级点位 4 个、 2 级点位 7 个、 1 级点位 3 个. 其中, 3 级点位有公元 1370 、 $1436 、 1673$ 年, 其中公元 1370-1436 年间存在辅助资料两条, 指示气候偏湿, 故将对应公元 $1397 、 1406$ 两年 调整为 4 级. 公元 1673 年资料指示开采方式为利用地下晶间卤水浇晒, 按标准应定为 4 级,但此时盐湖面积 记载仅为 “周回三里”, 为历史时期最小记录, 因此对该年份干湿情况调整为 3 级. 对照每百年资料留存情 况, 发现公元 1200-1300 年和公元 1700-1800 年内仅有资料一条, 数量明显不足, 且无法对其进行补充, 故 将两个时间段内的曲线改为虚线表达.

本文使用样条曲线对各散点进行连接,形成公元 1265-1949 年以来陕北定边盐湖指示的气候干湿变化 波动图 (图 2), 曲线表达更平滑, 可更清晰表达气候波动情况. 综合图 2 和表 8 分析, 可将过去千年陕北定边 盐湖区域内气候干湿变化特征依次表述为:1) 公元 1265 年前后区域内处于偏干时期. 2) 12 世纪末至 13 世 纪中叶,气候处于偏湿状态, 后期有转干迹象;3) 15 世纪中期至 17 世纪初是一个明显的干旱期,其中公元 1452-1557 年气候偏干,公元 1557-1614 年时干旱达到鼎盛, 为 1265 年以来最干燥时期;4) 17 世纪气候先 干后湿,变化幅度较大;5) 17 世纪末至 19 世纪末, 气候平稳, 长期处于偏湿状态;6) 20 世纪初存在一次短暂 的干湿急转状况, $1910 \mathrm{~s}$ 气候偏干, 至 $1940 \mathrm{~s}$, 气候转湿.

表 7 公元 996-1941 年各年份资料定级情况

Tab.7 Data classification of different years from 996 A.D. to 1941 A.D.

\begin{tabular}{cccccc}
\hline 时间(A.D.) & 等级 & 时间 (A.D.) & 等级 & 时间 (A.D.) & 等级 \\
\hline 1265 年 & 2 & 1540 年 & 2 & 1817 年 & 4 \\
1370 年 & 3 & 1542 年 & 2 & 1841 年 & 4 \\
1397 年 & 4 & 1557 年 & 1 & 1913 年 & 2 \\
1406 年 & 4 & 1602 年 & 1 & 1941 年 & 4 \\
1436 年 & 3 & 1607 年 & 1 & & \\
1452 年 & 2 & 1614 年 & 2 & & \\
1467 年 & 2 & 1673 年 & 3 & & \\
1500 年 & 2 & 1734 年 & 4 & & \\
\hline
\end{tabular}

(1)《明太宗实录》,卷 59 , “永乐四年九月壬戌” 条, 台北, “中研院”历史语言研究所缩印,第 0855 页.

(2)《神宗万历实录》卷 236, “万历十九年五月庚寅” 条, 台北, “中研院”历史语言研究所缩印,第 4384 页.

(3)《明宪宗实录》, 卷 39, “成化三年二月庚申” 条, 台北: “中研院”历史语言研究所编, 第 0794 页. 

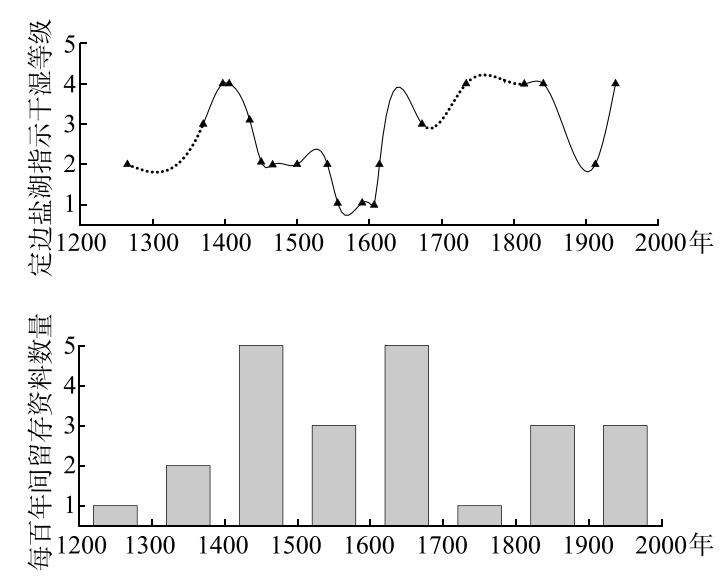

图 2 公元 1265 年以来定边盐湖指示区域干湿波动及每百年留存资料情况

Fig.2 Dry and wet fluctuation in indicator area of Dingbian salt lakes since 1265 A.D.

表 8 公元 1265 年以来陕北定边盐湖卤水赋存情况变化

Tab. 8 Changes of brine occurrence in Dingbian salt lakes since 1265 A.D.

\begin{tabular}{cccccc}
\hline 时期 (A.D.) & 气候干湿状况 & 时期( A.D.) & 气候干湿状况 & 时期( A.D.) & 气候干湿状况 \\
\hline 1265 年前后 & 偏干 & $1557-1614$ 年 & 干燥 & $1841-1913$ 年 & 转干 \\
$1370-1436$ 年 & 偏湿 & $1614-1673$ 年 & 转湿 & $1913-1949$ 年 & 偏湿 \\
$1436-1557$ 年 & 偏干 & $1673-1841$ 年 & 偏湿 & & \\
\hline
\end{tabular}

\section{4 讨论}

\section{1 季风边缘区内部气候干湿变化状况对比和差异分析}

将本文重建的定边盐湖指示的气候干湿变化序列与其他代用指标建立的序列进行对比, 分析造成干湿 变化波动的驱动力因素, 以及同一区域内部的差异问题.

前人研究表明西北地区的降水强弱, 与夏季风强弱关系紧密. 图 3 中 (a) 序列为 Zhang 等采集研究的万 象洞 WX42B 石笋 $\delta^{18} \mathrm{O}$ 同位素变化情况, 以指示公元 1810 年以来的夏季风强弱变化序列. 比对发现,定边盐 湖水位变化指示出过去千年内共存在 4 个湿润时期和 3 次干旱时期. 其中, 湿润期和干旱期都与 (a) 序列呈 现的趋势相同, 表明定边盐湖所在区域的气候干湿变化与夏季风的强弱有很好的对应关系, 有高度一致性. 具体表现为东亚夏季风强时, 陕北盐湖所在区域较湿润, 反之则相反. 可判断夏季风强度是影响定边盐湖所 处区域干湿变化的主要原因.

季风边缘区内部存在一定的差异性. 图 3 中 (b)、(c) 序列资料采集于岱海盆地, 位于内蒙古自治区乌兰 察布市凉城县, 与定边盐湖统属中国季风边缘区, 但定边盐湖位置靠西, 岱海则位于东部. (b) 序列为利用岱

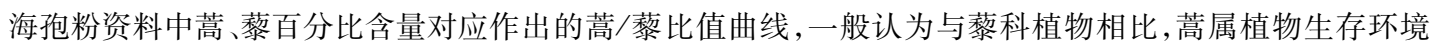

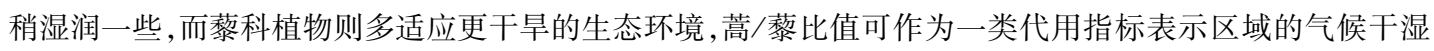
状况. 对比发现, 定边盐湖所在区域与岱海盆地在过去 $1000 \mathrm{a}$ 中气候干湿变化的趋势有明显的一致性, 其波 动状况与定边盐湖的卤水水位变化状况基本保持一致,证明两地气候在过去千年的气候干湿变化趋基本相 同. 但 1841 年后, 岱海蒿/栳比值曲线有一个明显迅速的下降, 而定边盐湖变化曲线相较存在迟缓, 造成 1841-1913 年间的变化两条曲线变化趋势不一致. 这是本文使用资料的响应延后性造成, 本文所用文献多 为地方志, 资料编䇣并非逐年, 而是阶段性编修,存在响应延后的情况.

图 3 中 (c) 序列为利用狍粉资料重建的岱海盆地过去 $1500 \mathrm{a}$ 降水量变化情况. 可发现岱海盆地的降水 量序列与定边盐湖水位变化序列两条曲线存在差异, 同一时段的对应关系并不明确. 岱海盆地与定边盐湖 


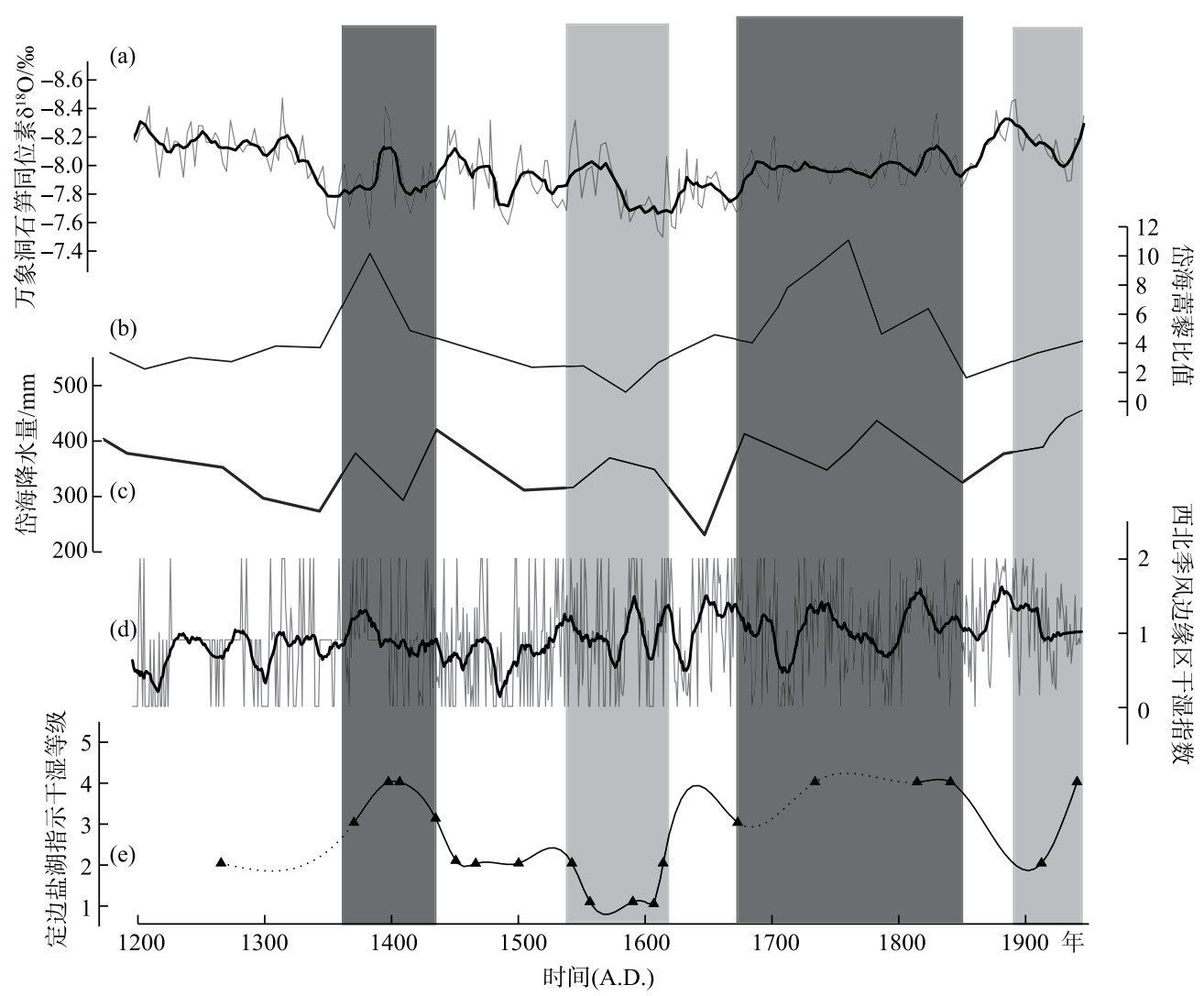

图 3 与同区域不同资料系统重建序列对比 (深色区域为定边盐湖指示的湿润时期,浅色区域为定边 盐湖指示的干旱时期. (a) 为万象洞 WX42B 石笋 $\delta^{18} \mathrm{O}$ 同位素变化序列, 粗黑线为 $30 \mathrm{a}$ 滑动平均曲线,

细黑线为 $10 \mathrm{a}$ 滑动平均曲线; (b) 为孢粉记录重建的岱海盆地过去 $1500 \mathrm{a}$ 间的降水量重建序列;

(c) 为岱海盆地狍粉资料中的蒿㢣比值变化序列; (d) 为利用历史文献重建的中国西北季风边缘 区干湿指数序列, 粗黑线为 $30 \mathrm{a}$ 滑动平均曲线, 细黑线为逐年变化曲线; (e) 为本文重建结果 ${ }^{[24-26]}$ )

Fig.3 Comparison of reconstructed sequences with different data systems in the same region

(The dark area is the wet period indicated by the Dingbian salt lake, and the light area is the dry period.

(a) is the WX42B $\delta^{18} \mathrm{O}$ record; the thick black line is the 30-year sliding average curve,

the thin black line is the 10-year moving average curve; (b) is the precipitation reconstruction sequence of the Daihai Basin in past 1500 years reconstructed by using pollen records; (c) is the variation of the Artemisia quinoa ratio in the pollen data of the Daihai Basin; (d) is the dry and wet index sequence of the northwest monsoon marginal area of China reconstructed by using historical literature,

The thick black line is the 30 -year moving average curve, and the thin black line is the year-by-year change curve; (e) is the reconstruction result of this paper ${ }^{[24-26]}$ )

直线距离相隔 $549 \mathrm{~km}$, 且两湖所处的局地环境存在差异, 降水序列有所异同是有可能的. 但有一关键点需要 提出, 本文重建的定边盐湖演变序列不存在统一的时间分辨率, 而岱海降水量变化序列的理论时间分辨率 达到 22 和 $34 \mathrm{a}$, 导致两条序列在一些特定时间段上存在不一致. 此外, 本文所用资料以文献资料为主,一些 变化点,会因文献编修情况限制无法及时记录,或未记录,无法对变化做出响应,变化时间点存在提前或延 后, 这在与其他序列对比的时候也会出现, 文献资料记录的部分内容不真实和时间不确定,造成了本文重建 序列的不确定,现有技术手段无法对此类不确定性进行修正,故暂时无法避免. 
针对定边盐湖所在区域气候干湿变化的研究, 不同资料类型得出的结果也有一定的区别. 图 3 中 (d) 序 列以历史文献中的水旱灾害史料为核心重建, 其利用《中国三千年气象记录总集》、《西北灾荒史》等资料, 选取中国西北季风边缘区内甘肃东南部、宁夏省、陕西西北部以及内蒙古部分地区 21 个府级 (统县) 政区站 点内的文献资料, 并依照干湿指数得计算方法得出相关数据, 并形成逐年变化序列. 过去千年干湿变化的总 体趋势上, 干湿指数序列与定边盐湖卤水水位序列基本保持一致, 但在局部变化上有所出人. 干湿指数序列 指示西北地区最干旱时期为公元 1500 年前后, 在公元 1600-1700 年间气候波动较大, 总体偏湿, 过去千年 西北的干湿变化大体以公元 1500 年为界, 1500 年前较干,而 1500 年后较湿. 而定边盐湖则指示公元 1600 年前后为区域内最干旱时期, 后突然转湿, 过去千年有 3 次明显分异, 分别以公元 1300 年前后和公元 1600 年前后为界.

图 3 中 (d)、(e) 两条曲线在公元 1500-1600 年间的波动状况反映情况存在矛盾. 分析发现, 干湿指数 序列基于农业收成资料形成, 数据采集区域大,包含整个西北疾风边缘区 21 个县级行政区, 区域范围内除 农牧交错带外, 还有一些灌溉农业区存在, 文献记录受人类活动影响较大. 其中所采集范围内的银川站、延 安站等农业区内人类工程设施较多, 降低了气候干湿变动对农业的影响, 且这类灌溉农业为主的站点保存 资料较农牧交错区资料多, 会影响重建结果客观性; 其次, 干湿指数序列在公元 1600-1700 年间的数据量较 其余时段数据明显较少, 且数据波动很大, 该序列通过取滑动平均值的方法, 容易对该时段出现的极值判断 出现偏差. 定边盐湖重建序序列所用指标, 其本质上是一种可以指示区域地下水位的代用指标, 其较水旱灾 害资料更客观, 在一定程度上可弥补水旱资料的判断误区, 对该区域的干湿变化状态有更清晰的表达.

\section{2 不同区域气候干湿状况变化差异}

本文选择东部季风区、非季风区以及西风季风交错区的气候干湿波动重建序列与本文重建结果对比, 分析中国西北的季风边缘区气候干湿变化与其他区域干湿波动的差异性.

对比发现, 图 4 中 (a) 序列表示 Zheng 等重建的东部季风区气候干湿变化状况 ${ }^{[27]}$, 反映了中国东部季风 区的气候干湿变化, 与定边盐湖所在区域的干湿变化序列在过去千年中, 湿润时期出现时间较为一致. 其中 公元 1400 年前后、公元 1800 年前后的两个湿润时期序列波动趋势相同, 表明湿润时期夏季风强度较高, 东 部季风区范围内整体较湿润. 而定边盐湖指示为干旱状态的时期, 东部季风区则处于一个较湿润的情况, 例 如公元 1300 年前后、公元 1600 年前后和公元 1900 年前后时段内, 两条曲线表达的趋势相反. 表明夏季风强 度减弱后, 对季风边缘区的影响强度明显大于季风区核心区域.

图 4 中 (b) 序列为郡雪梅等重建的柴达木盆地东北部降水量波动序列 ${ }^{[28]}$, 指代的是非季风区的气候干 湿变化情况. 对比发现, 两条曲线没有明确的对应关系, 表明影响两区域气候干湿的因素并不相同, 季风边 缘区与非季风区的气候干湿变化有很大的差异.

同样的情况发生在定边盐湖与青海湖的对比当中, 图 4 中 (c) 序列为沈吉等重建的千年来青海湖沉积 记录中的湖芯碳酸盐变化序列 ${ }^{[15]}$, 指代东南、西南季风与西风带交汇区域的干湿变化序列. (c)、(d) 两条序 列对比可知, 两条序列显示的湿润期有较好的一致性, 但在干旱期内则出现了相反的情况. 青海湖所在区域 为季风和西风交替控制区域, 影响其气候干湿变化的因子较多且复杂, 而定边盐湖则深处内陆, 影响其降水 的因子比较单一, 从而影响了两条路曲线的趋势变化.

需要明确的是柴达木树轮、东部历史文献和青海湖沉积 3 种资料所指代的要素并非完全是气候干湿变 化指标, 影响其变化的因素较多, 物理机制复杂, 故其表示的干湿状态并不明确. 而定边盐湖卤水水位演变 的影响因素相较简单, 所指代的情况直接指向气候干湿变化, 是一种指示意义更明确、准确可靠的代用指标.

\section{5 结论}

1) 公元 1265-1949 年陕北定边盐湖卤水水位演变序列可较好指示盐湖所处区域干湿变化波动状况. 公元 1265-1949 年间共存在 2 个湿润期和 3 个干旱期. 其中, 公元 1557-1614 年为公元 1265 年以来最干 旱时期,这一情况在旱涝史料记录中表达不明确.

2) 影响中国西北季风边缘区干湿状态波动的原因为东亚夏季风的强弱变化, 影响因子单一, 季风边缘 区内部的干湿状态变化趋势基本相同. 


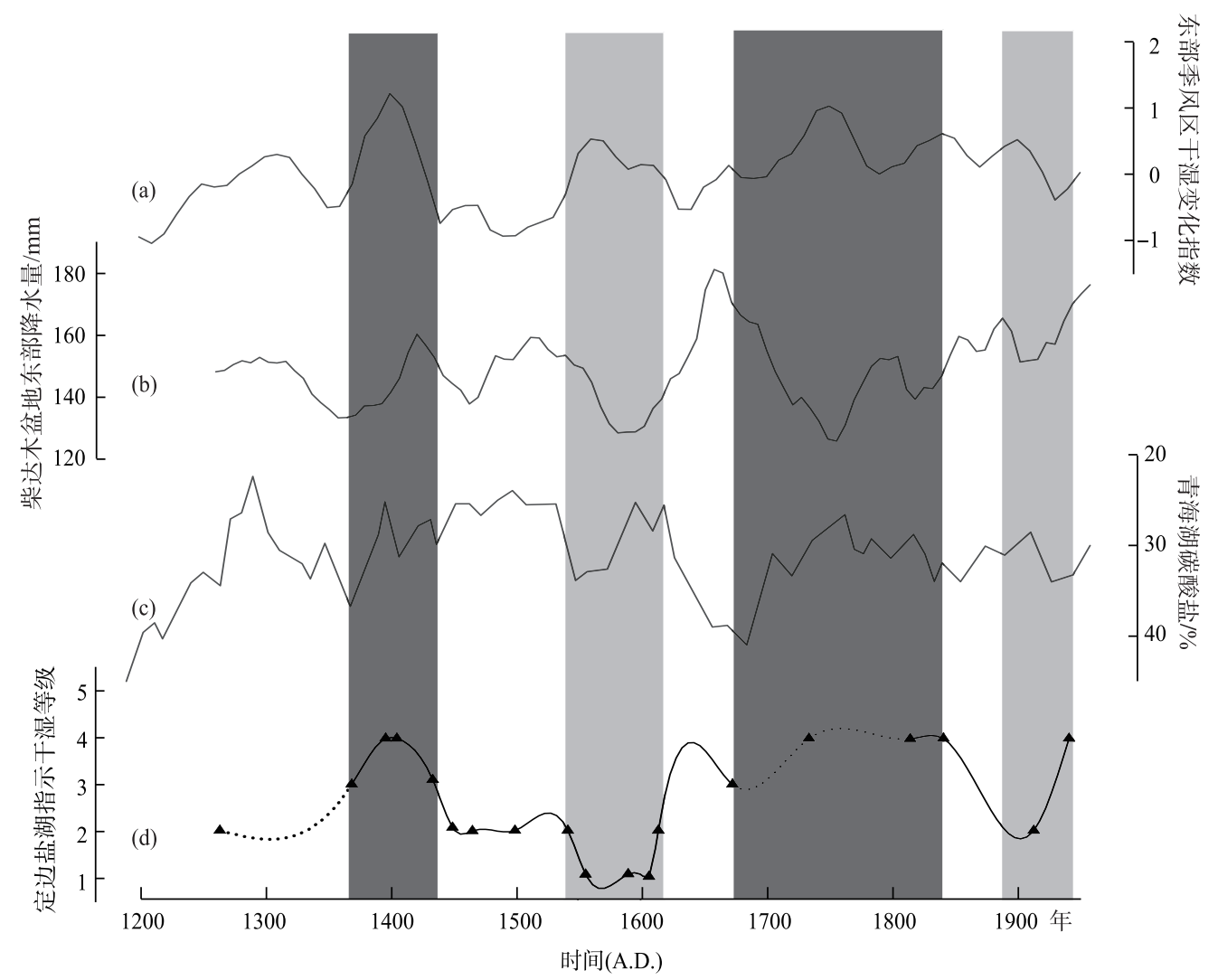

图 4 与不同区域气候干湿变化序列对比（深色区域为定边盐湖指示的湿润时期,浅色区域为定边 盐湖指示的干旱时期. (a) 为历史文献重建的过去 $1500 \mathrm{a}$ 东部季风区干湿指数变化序列;

(b) 序列为利用树轮资料重建的柴达木盆地东北部降水量波动序列; (c) 为千年来青海湖湖泊 沉积记录中的的湖芯碳酸盐变化序列; (d) 序列为本文重建结果 ${ }^{[15,27-28]}$ )

Fig.4 Comparison with the dry and wet climate change series in different regions ( The dark area is the wet period indicated by the Dingbian salt lake, and the light area is the dry period.

(a) is the sequence of variation in the wet and dry index in the eastern monsoon region over

1500 years reconstructed by historical literature; ( b ) is the sequence of precipitation fluctuation in the northeastern part of the Qaidam Basin reconstructed by tree ring data; (c) is the sequence of lake core carbonate change in the lake sediment record; $(d)$ is the reconstruction result of this paper ${ }^{[15,27-28]}$ )

3 ) 历史文献中记载的湖泊演变信息是一种有效的自然证据,可为季风边缘区湖泊研究提供新的数据. 但受限于历史文献的数量和质量, 该类数据时间连续性较差, 若能与传统湖泊沉积资料有效结合, 会具有更 广阔的研究前景.

\section{6 参考文献}

[ 1 ] Shi YF, Shen YP, Kang ES et al. Recent and future climate change in northwest China. Climatic Change, 2007, 80(3/ 4) : 379-393. DOI: 10.1007/s10584-006-9121-7.

[ 2 ] An ZS. The history and variability of the East Asianpaleomonsoon climate. Quaternary Science Reviews, 2000, 19(1/2/3/ 4/5) : 171-187. DOI: 10.1016/S0277-3791(99)00060-8.

[ 3 ] Ding YH, Chan JCL. The East Asian summer monsoon: An overview. Meteorology and Atmospheric Physics, 2005, 89(1/) 2/3/4) : 117-142. DOI: 10.1007/s00703-005-0125-z. 
[ 4 ] Yang JP, Ding YJ, Chen RS et al. Relationship of Asian Monsoon with dry and wet climate boundary and agro-pasturing climate boundary. Scientia Geographica Sinica, 2005, 25(4): 441-447. [杨建平, 丁永建, 陈仁升等. 亚洲季风与中 国干湿、农牧气候界线之关系. 地理科学, 2005, 25(4): 441-447.]

[ 5 ] Gu YJ, Wang HL, Liu J. Latitude-dependent response of east Asian summer monsoon to external forcing in the last millennium. Acta Meteorologica Sinica, 2010, 24(6) : 671-679. DOI: 10.3319/TA0.2010.05.03.01( T).

[ 6 ] Chen FH, Chen JH, Holmes J et al. Moisture changes over the last millennium in arid central Asia: A review, synthesis and comparison with monsoon region. Quaternary Science Reviews, 2010, 29(7/8) : 1055-1068. DOI: 10.1016/j.quascirev.2010.01.005.

[ 7 ] Gao SY, Wang GY, Ha S et al. A case study on desert evolution in the northwestern fringe of monsoon area, China since the last glacial epoch. Quaternary Sciences, 2001, 21(1):66-71. [高尚玉, 王贵勇, 哈斯等. 末次冰期以来中国季风 区西北边缘沙漠演化研究. 第四纪研究, 2001, 21(1): 66-71.]

[ 8 ] Long H, Wang NA, Liu Y et al. Mid-Holocene climate variations from lake records of the east Asian monsoon margin: A multi-proxy and geomorphological study. Quaternary Sciences, 2007, 27(3): 371-381. [隆浩, 王乃昂, 李育等. 猪野泽 记录的季风边缘区全新世中期气候环境演化历史. 第四纪研究, 2007, 27(3): 371-381.]

[ 9 ] Sun AZ, Ma YZ, Feng ZD et al. The pollen record and the paleoclimate evolution since 13.0-7.0 ${ }^{14} \mathrm{C}$ ka BP in the south of Ningxia. Chinese Science Bulletin, 2007, 52(3) : 324-331. [孙爱芝, 马玉贞, 冯兆东等. 宁夏南部 $13.0 \sim 7.0{ }^{14} \mathrm{C} \mathrm{ka}$ BP 期间的孢粉记录及古气候演化. 科学通报, 2007, 52(3) : 324-331.]

[10] Wang SM, Li JR. Lake sediment-an effective method for studying historical climate-taking Qinghai Lake and Daihai as examples. Chinese Science Bulletin, 1991, 36(1): 54-56. [王苏民, 李建仁. 湖泊沉积一一研究历史气候的有效手 段一一青海湖、岱海为例. 科学通报, 1991, 36(1): 54-56.]

[11] Zhang ZK, Wu RJ, Wang SM. Implication of magnetic frequency dependent susceptibility on environmental variation from lacustrine sediment inDaihai Lake. Geographical Research, 1998, 17(3): 297-302. [张振克, 吴瑞金, 王苏民. 岱海湖 泊沉积物频率磁化率对历史时期环境变化的反映. 地理研究, 1998, 17(3) : 297-302.]

[12] Cao JT, Wang SM, Shen J et al. The paleoclimate changes during the past millennium lnferred from the lacustrine core in Daihai Lake, Inner Mongolia. Scientia Geographica Sinica, 2000, 20(5): 391-396. [曹建廷, 王苏民, 沈吉等. 近千年 来内蒙古岱海气候环境演变的湖泊沉积记录. 地理科学, 2000, 20(5): 391-396. ]

[13] Cao JT, Shen J, Wang SM. A preliminary study of climate change during the little ice age inferred from lacustrine sediments inDaihai Lake, Inner Mongolia. J Lake Sci, 2000, 12(2) : 97-104. DOI: 10.18307/2000.0201. [ 曹建廷, 沈吉, 王苏民. 内蒙古岱海湖泊沉积记录的小冰期气候环境. 湖泊科学, 2000, 12(2): 97-104.]

[14] Jin ZD, Shen J, Wang SM et al. The medieval warm period in the Daihai area. J Lake Sci, 2002, 14(3) : 209-216. DOI: 10.18307/2002.0303. [ 金章东, 沈吉, 王苏民等. 岱海的“中世纪暖期”. 湖泊科学, 2002, 14(3) : 209-216.]

[15] Shen J, Zhang EL, Xia WL. Records from lake sediments of the Qinghai Lake to mirror climatic and environmental changes of the past about 1000 years. Quaternary Sciences, 2001, 21(6): 508-513. [沈吉, 张恩楼, 夏威岗. 青海湖近千年来 气候环境变化的湖泊沉积记录. 第四纪研究, 2001, 21(6) : 508-513.]

[16] Zhang XG. The evolution ofYunmengze Lake and the formation of the Lower Jingjiang River. Fudan Journal: Social Sciences Edition, 1980, 22(2): 40-48. [张修桂. 云梦泽的演变与下荆江河曲的形成. 复旦学报: 社会科学版, 1980, $22(2): 40-48$. ]

[17] Tan QX, Zhang XG. Poyang Lake, the historical process of evolution. Fudan Journal: Social Sciences Edition, 1982, (2) : 42-51. [谭其榱, 张修桂. 鄱阳湖演变的历史过程. 复旦学报: 社会科学版, 1982, (2) : 42-51.]

[18] Zhang XG. The course of the Taihu Lake's evolution in historical period. Journal of Chinese Historical Geography, 2009,24 (1) : 5-12. [张修桂. 太湖演变的历史过程. 中国历史地理论丛, 2009, 24(1): 5-12.]

[19] Bai XR. Depositional characteristic of the salt lake in the Dingbian, Shaanxi. Journal of Northwest University, 1992,22 (4) : 457-463. [ 白学让. 定边盐湖盐类沉积特征. 西北大学学报: 自然科学版, 1992, 22(4) : 457-463.]

[20] Zheng XY, Zhang MG, Xu C et al eds. Salt lakes of China. Beijing: Science Press, 2002. [郑喜玉, 张明刚, 徐昶等. 中 国盐湖志. 北京: 科学出版社, 2002.]

[21] Ma Ml. Quyan or Qiuci-A textual research on the ancient city of Zhangjiachang, Yanchi County, Ningxia. China's Borderland History and Geography Studies, 2019, 29(4) : 35-47. [马孟龙. 昫衍抑或龟兹一一宁夏盐池县张家场古城考辨. 中国边疆史地研究, 2019, 29(4): 35-47.] 
[22] Chen YZ ed. A study on Quyan, Yanzhou, and Hua Ma Chi. Journal of Ningxia University, 1984, 1: 66-70. [ 陈永中. 朐 衍、盐州、花马池考. 宁夏大学学报: 社会科学版, 1984, 1: 66-70.]

[23] Zhang WJ ed. Studies on the water dynamic and the regional deserification characteristics in Yanchi Sandland. Yinchuan: Ningxia People's Publishing House, 2004. [张维江. 盐池沙地水分动态及区域荒漠化特征研究. 银川: 宁夏人民出 版社, 2004.]

[24] Zhang P, Cheng H, Edwards RL et al. A test of climate, sun, and culture relationships from an 1810-year Chinese cave record. Science, 2008, 322 (5903) : 940-942. DOI: 10.1126/science.1163965.

[25] Xu QH, Xiao JL, Zhong C et al. Climate changes of Daihai Basin during the past 1500 from a pollen record. Quaternary Sciences, 2004, 24(3) : 341-347. [许清海, 肖举乐, 中村俊夫等. 孢粉记录的岱海盆地 1500 年以来气候变化. 第 四纪研究, 2004, 24(3) : 341-347.]

[26] Yang YD, Han JF, Cheng SN. The reconstruction of dry and wet variation in monsoon boundary zone of northwest China by records of historical documents over the past millennium. Journal of Earth Environment, 2014, 5(6) : 392-399. [ 杨显达, 韩健夫, 成赛男. 过去千年西北季风边缘区干湿变化的重建及分析. 地球环境学报, 2014, 5(6): 392-399.]

[27] Zheng JY, Wang WC, Ge QS et al. Precipitation variability and extreme events in eastern China during the past 1500 years. Terrestrial, Atmospheric and Oceanic Sciences, 2006, 17(3) : 579. DOI: 10.3319/tao.2006.17.3.579(a).

[28] Shao XM, Liang EY, Huang L et al. A reconstructed precipitation series over the past millennium in the northeastern Qaidam basin. Advances in Climate Change Research, 2006, 2(3):122-126. [邵雪梅, 梁尔源, 黄否等. 柴达木盆地东北部 过去 1437a 的降水变化重建. 气候变化研究进展, 2006, 2(3) : 122-126.] 